\title{
von Willebrand Factor and Oxidative Stress Parameters in Acute Coronary Syndromes
}

\author{
Zoran Koprivica, ${ }^{1}$ Dusica Djordjevic, ${ }^{2}$ Milena Vuletic, ${ }^{2}$ Vladimir Zivkovic, ${ }^{2}$ \\ Nevena Barudzic, ${ }^{2}$ Nebojsa Andjelkovic, ${ }^{2}$ Dragan Djuric, ${ }^{3}$ Violeta Iric-Cupic, ${ }^{4}$ \\ Jelena Krkeljic, ${ }^{2}$ and Vladimir Jakovljevic ${ }^{2}$ \\ ${ }^{1}$ Health Centre, 32300 Gornji Milanovac, Serbia \\ ${ }^{2}$ Department of Physiology, Faculty of Medicine, University of Kragujevac, 34000 Kragujevac, Serbia \\ ${ }^{3}$ Institute of Physiology "Richard Burian", School of Medicine, University of Belgrade, 11000 Belgrade, Serbia \\ ${ }^{4}$ University Hospital Centre "Kragujevac" and Faculty of Medicine, University of Kragujevac, 34000 Kragujevac, Serbia
}

Correspondence should be addressed to Vladimir Jakovljevic, drvladakgbg@yahoo.com

Received 17 February 2011; Accepted 7 June 2011

Academic Editor: Kenneth Maiese

Copyright ( $) 2011$ Zoran Koprivica et al. This is an open access article distributed under the Creative Commons Attribution License, which permits unrestricted use, distribution, and reproduction in any medium, provided the original work is properly cited.

\begin{abstract}
Considering the role of von Willebrand factor (vWf) in hemostasis, and the role of oxidative stress in the development of endothelial dysfunction and atherosclerotic disease, the aim of our study was to investigate the relationship between vWf, parameters of oxidative stress and different types of acute coronary syndromes (ACS). Levels of vWf activity (vWfAct), vWf antigen (vWfAg), nitric oxide (estimated through nitrites- $\mathrm{NO}_{2}{ }^{-}$), superoxide anion radical $\left(\mathrm{O}_{2}{ }^{-}\right.$), hydrogen peroxide $\left(\mathrm{H}_{2} \mathrm{O}_{2}\right)$, index of lipid peroxidation (estimated through thiobarbituric acid reactive substances-TBARS), superoxide dismutase (SOD) and catalase (CAT) activity of 115 patients were compared with those of 40 healthy controls. ACS patients had significantly higher vWfAct and vWfAg levels, as well as TBARS levels, while their levels of $\mathrm{NO}_{2}{ }^{-}, \mathrm{H}_{2} \mathrm{O}_{2}$, SOD and CAT activities were lower than controls'. vWfAg showed high specificity and sensitivity as a test to reveal healthy or diseased subjects. Multivariant logistic regression marked only vWfAg and TBARS as parameters that were under independent effect of ACS type. The results of our study support the implementation of vWf in clinical rutine and into therapeutic targets, and suggest that ACS patients are in need of antioxidant supplementation to improve their impaired antioxidant defence.
\end{abstract}

\section{Introduction}

Under physiological conditions, the vascular endothelium produces many substances that contribute importantly to hemostasis, fibrinolysis, and regulation of vessel tone and permeability [1]. One such substance is glycoprotein von Willebrand factor (vWf), which is almost exclusively produced by the endothelium, and thus is a marker of endothelial activation or dysfunction [2-4]. vWf mediates platelet adhesion to the vascular wall, platelet aggregation and serves as a plasma carrier for factor VIII, stabilizing it in the circulation [5]. Since almost all acute coronary syndromes (ACSs) result from thrombus formation in pre-existing atherosclerosis [1], and given the key role of vWf in arterial thrombus formation, this biomarker attracted considerable interest as a predictor of cardiovascular disease (CVD) $[1,5]$. Previously published studies suggest that there is a weak association between vWf plasma levels and risk of coronary heart disease (CHD) in general population, but its predictive value significantly rises in patients with preexisting vascular disease, diabetics, and the elderly [6-9]. It was noticed that vWf rises during the course of ACSs $[4,10,11]$, and it is thought that $\mathrm{vWf}$ is not only a marker, but also a mediator in the pathogenesis of myocardial infarction (MI) [1]. Although a number of studies pointed out the prognostic value of $\mathrm{vWf}$ [12-14], there is still a long way to go before plasma vWf levels can be used as a predictor of cardiovascular disease in clinical practice [5].

von Willebrand factor can be produced and released by endothelial cells by a variety of stimuli in vitro and in vivo 


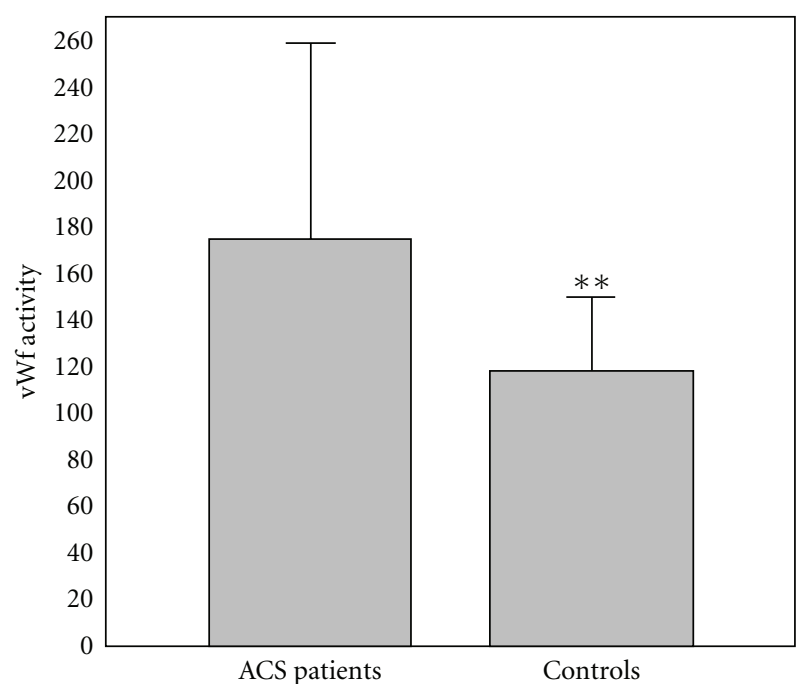

Figure 1: Values of von Willebrand factor activity (\%) in group of ACSs patient and in group of control subjects (mean + SD). Compared with control subjects, ACSs patients had statistically higher levels of vWfAct $(175.27 \pm 86.52$ (166.0) \% compared with $118.35 \pm 33.11$ (122.0) \%; Mann-Whitney $U$ test; $\left.{ }^{* *} P<0.01\right)$.

TABLE 1: Demographic characteristics of investigated groups.

\begin{tabular}{lcc}
\hline Parameters & ACSs patients & Controls \\
\hline Number of patients $(n)$ & 115 & 40 \\
Sex (male/female) & $74 / 41$ & $26 / 14$ \\
Age $(X \pm$ SD years $)$ & $67.0 \pm 8.0$ & $65.0 \pm 3.0$ \\
\hline
\end{tabular}

$[5,15,16]$. A number of substances regulate endothelial release of vWf. Among other secretion agonists and antagonists, like numerous mediators of inflammation and/or thrombosis, reactive oxygen species (ROS) play an important role. For example, superoxide anion radical $\left(\mathrm{O}_{2}^{-}\right)$is considered to be activator of endothelial exocytosis [17], while hydrogen peroxide $\left(\mathrm{H}_{2} \mathrm{O}_{2}\right)$ has been shown to inhibit thrombin-induced vWf secretion in a dose-dependent manner [18]. On the other hand, $\mathrm{H}_{2} \mathrm{O}_{2}$ induced a weak secretory response [19]. Thus, the effects of $\mathrm{H}_{2} \mathrm{O}_{2}$ are still to be investigated. Nitric oxide (NO) is another reactive substance that exhibits inhibitory effects on vWf secretion, but its effects are also yet to be elucidated, since the majority of research was performed on cultured endothelial cells, which may not be the ideal tool to study the effects of nitric oxide (NO) [5].

Emerging data suggest that acute presentations of coronary artery disease may involve a complex interplay between the vessel wall, inflammatory cells, and the coagulation cascade. Considering the role of vWf in hemostasis and the role of oxidative stress in the development of endothelial dysfunction and atherosclerotic disease [20-23], the aim of our study was to investigate the relationship between von Willebrand factor and parameters of oxidative stress on the one side and different types of acute coronary syndromes on the other.

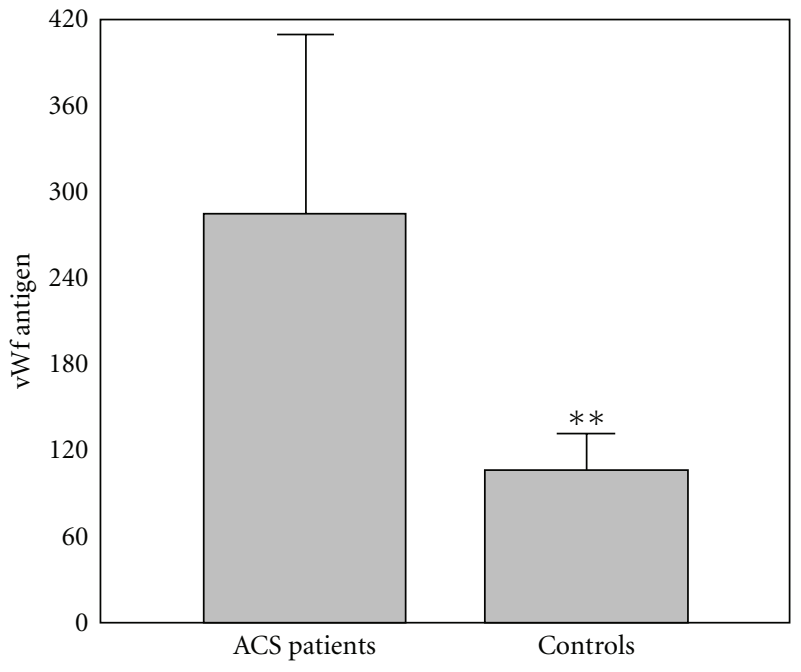

FIGURE 2: Values of von Willebrand factor antigen (\%) in group of ACSs patient and in group of control subjects (mean + SD). Compared with control subjects, ACSs patients had statistically higher levels of vWfAg $(284.82 \pm 126.66$ (261.0) \% compared with $104.57 \pm 25.52$ (108.0) \%; $t$-test; $\left.{ }^{* *} P<0.01\right)$.

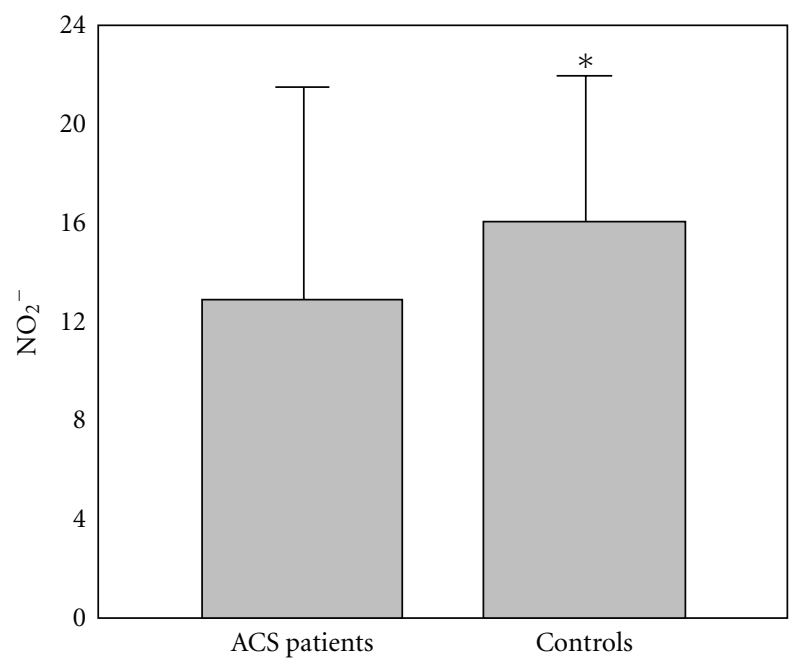

FIGURE 3: Values of nitric oxide (nitrites) levels ( $\mathrm{nmol} / \mathrm{mL}$ ) in group of ACSs patient and in group of control subjects (mean + SD). Compared with control subjects, ACSs patients had statistically lower levels of $\mathrm{NO}_{2}{ }^{-}(12.88 \pm 8.40(10.52) \mathrm{nmol} / \mathrm{mL}$ compared with $15.98 \pm 6.05(17.20) \mathrm{nmol} / \mathrm{mL}$; Mann-Whitney $U$ test; $* P<0.05)$.

\section{Results}

Demographic data of investigated groups are shown in Table 1.

The results of comparison of investigated biochemical parameters in patients and controls are shown in Figures 1, $2,3,4,5,6,7,8$, and 9 .

Results of uni- and multivariant logistic regression related to the effects of ACSs existence to changes in examined biochemical parameters are shown in Table 2. Results of univariant logistic regression marked vWfAg, vWfAct, $\mathrm{NO}_{2}{ }^{-}$, 
TABLE 2: Results of uni- and multivariant logistic regression related to the effects of ACSs existence to changes in examined biochemical parameters ( $\exp B$-relative risk; $\mathrm{CI}$-confidence interval; ${ }^{*} P<0.005 ;{ }^{*} P<0.001$ ).

\begin{tabular}{|c|c|c|c|c|}
\hline \multirow{2}{*}{ Parameter } & \multicolumn{2}{|c|}{ Univariant logistic regression } & \multicolumn{2}{|c|}{ Multivariant logistic regression } \\
\hline & $\exp B(95 \% \mathrm{CI})$ & Sig. & $\exp B(95 \% \mathrm{CI})$ & Sig. \\
\hline vWfAct & $0.988(0.981-0.994)$ & $P=0.000^{* *}$ & $1.033(0.984-1.084)$ & $P=0.193$ \\
\hline vWfAg & $0.962(0.947-0.976)$ & $P=\mathbf{0 . 0 0 0}^{* *}$ & $0.912(0.810-1.027)$ & $P=0.130$ \\
\hline $\mathrm{NO}_{2}^{-}$ & $1.062(1.012-1,114)$ & $P=0.014^{* *}$ & $1.010(1.002-1.114)$ & $P=0.914$ \\
\hline $\mathrm{O}_{2}^{-}$ & $1.005(0.983-1.028)$ & $P=0.643$ & - & - \\
\hline $\mathrm{H}_{2} \mathrm{O}_{2}$ & $1.254(1.124-1.400)$ & $P=0.000^{* *}$ & $1.054(1,024-1.300)$ & $P=0.988$ \\
\hline TBARS & $0.399(0.251-0.635)$ & $P=0.000^{* *}$ & $0.999(0.990-1.100)$ & $P=0.999$ \\
\hline SOD & $1.007(1.004-1.011)$ & $P=0.000^{* *}$ & $1.017(1.004-1.031)$ & $P=0.899$ \\
\hline CAT & $1.046(0.980-1.117)$ & $P=0.174$ & - & - \\
\hline
\end{tabular}

TABLE 3: Frequencies of elevated levels of vWfAct and vWfAg in ACSs patients and controls.

\begin{tabular}{|c|c|c|c|c|}
\hline & & \multicolumn{2}{|c|}{ Group } & \multirow{2}{*}{ Sig. } \\
\hline & & ACSs & Controls & \\
\hline \multirow{2}{*}{ vWfAg } & Elevated levels & $99(86.1 \%)$ & $0(0.0 \%)$ & \multirow{2}{*}{$P=0.000^{* *}$} \\
\hline & Normal levels & $16(13.9 \%)$ & $40(100.0 \%)$ & \\
\hline \multirow{2}{*}{ vWfAct } & Elevated levels & $62(53.9 \%)$ & $1(2.5 \%)$ & \multirow{2}{*}{$P=0.000^{* *}$} \\
\hline & Normal levels & $53(46.1 \%)$ & $39(97.5 \%)$ & \\
\hline
\end{tabular}

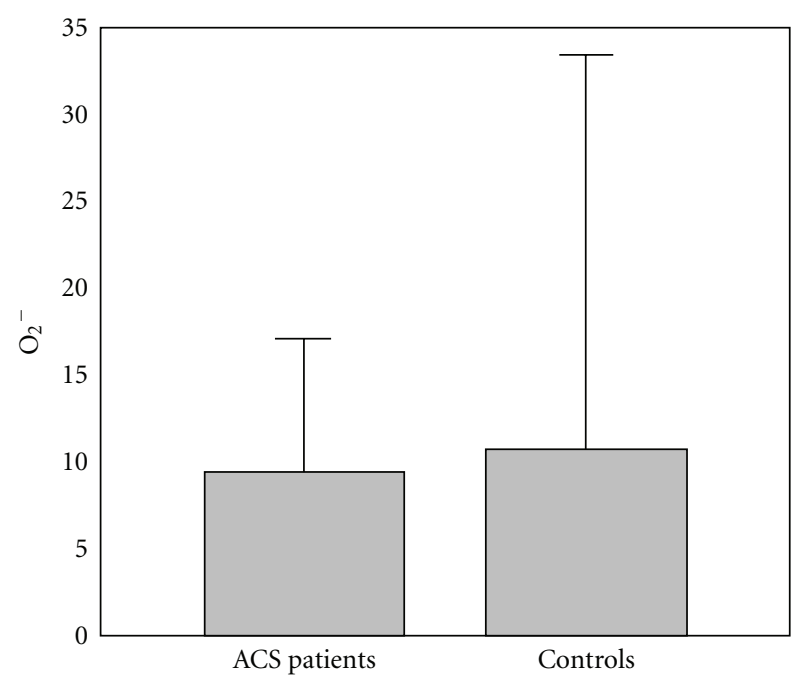

FIgURe 4: Values of superoxide anion radical levels $(\mathrm{nmol} / \mathrm{mL})$ in group of ACSs patient and in group of control subjects (mean + SD). ACSs patients and controls did not differ in levels of $\mathrm{O}_{2}{ }^{-}(9.34$ + $7.83(7.58) \mathrm{nmol} / \mathrm{mL}$ compared with 10.63 + 22.90 (5.27); Mann Whitney $U$ test; $P>0.05)$.

$\mathrm{H}_{2} \mathrm{O}_{2}$, TBARS, SOD, and CAT as significant. Univariant logistic regression shows the existence of differences in investigated parameters in existance of all other factors, while multivariant logistic regression marks parameters that are changed under independent effect of ACSs existance. Multivariant logistic regression did not mark any parameter as significant.

Frequency of elevated levels of vWfAct (above 163, range of referent values 48.8\%-163\%) and vWfAg (above 158,

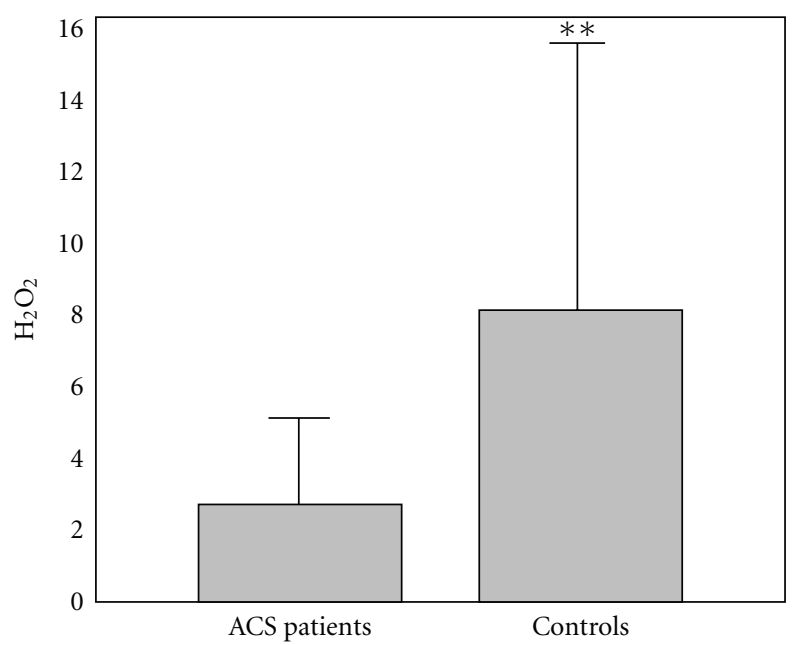

FIGURE 5: Values of hydrogen peroxide $(\mathrm{nmol} / \mathrm{mL})$ in group of ACSs patient and in group of control subjects (mean + SD). Compared with control subjects, ACSs patients had statistically lower levels of $\mathrm{H}_{2} \mathrm{O}_{2}(2.75 \pm 2.56(2.12) \mathrm{nmol} / \mathrm{mL}$ compared with $8.11 \pm 7.52$ (5.21); Mann Whitney $U$ test; $\left.{ }^{* *} P<0.01\right)$.

range of reerent values: $61.3 \%-158 \%$ ) in ACSs patients and controls are shown in Table 3. $\chi^{2}$ test showed that groups of ACSs patients and controls differed significantly in frequency of elevated levels of both vWfAct and vWfAg $(P=0.000$ for both).

Based on the data presented in Table 3, sensitivity and specificity of the test (measuring vWfAct and vWfAg levels) were calculated. Sensitivity, as an indicator of the test's ability to reveal patients with disease (ACSs) was 53.91\% for vWfAct and $86.0 \%$ for vWfAg, while specificity, as an indicator of 
TABLE 4: Levels of investigated biochemical parameters in different subgroups of subjects.

\begin{tabular}{|c|c|c|}
\hline & $X \pm \mathrm{SD}($ median $)$ & Sig. \\
\hline \multicolumn{3}{|c|}{ vWfAct (\%) } \\
\hline STEMI $(n=65)$ & $185.36 \pm 95.25(170.00)$ & $\begin{array}{c}\text { Kruskal-Wallis test: } P=\mathbf{0 . 0 0 0}^{* *} \\
\text { Mann-Whitney } U \text { test: }\end{array}$ \\
\hline NSTEMI $(n=36)$ & $167.92 \pm 75.56(168.50)$ & $\begin{array}{l}\text { STEMI versus NSTEMI } P=0.173 \\
\text { STEMI versus UA } P=0.072\end{array}$ \\
\hline $\mathrm{UA}(n=14)$ & $130.48 \pm 50.34(121.00)$ & $\begin{aligned} \text { STEMI versus Control } P & =\mathbf{0 . 0 0 0} \\
\text { NSTEMI versus UA } P & =0.214\end{aligned}$ \\
\hline Control $(n=40)$ & $118.35 \pm 33.11(122.00)$ & $\begin{array}{c}\text { NSTEMI versus Control } P=\mathbf{0 . 0 0 1}^{* *} \\
\text { UA versus Control } P=0.819\end{array}$ \\
\hline \multicolumn{3}{|c|}{ vWfAg (\%) } \\
\hline STEMI & $317.21 \pm 139.50(302.00)$ & $\begin{array}{c}\text { ONE way ANOVA: } P=\mathbf{0 . 0 0 0} * * \\
\text { Bonferroni: }\end{array}$ \\
\hline NSTEMI & $256.40 \pm 95.23(229.25)$ & $\begin{array}{l}\text { STEMI versus NSTEMI } P=\mathbf{0 . 0 1 2} \\
\text { STEMI versus UA } P=\mathbf{0 . 0 0 0}^{* *}\end{array}$ \\
\hline UA & $169.27 \pm 52.47(181.50)$ & $\begin{array}{l}\text { STEMI versus Control } P=\mathbf{0 . 0 0 0} * * \\
\text { NSTEMI versus UA } P=\mathbf{0 . 0 2 1 ^ { * }}\end{array}$ \\
\hline Control & $104.57 \pm 25.52(108.00)$ & $\begin{array}{c}\text { NSTEMI versus Control } P=\mathbf{0 . 0 0 0}^{* *} \\
\text { UA versus Control } P=0.991\end{array}$ \\
\hline \multicolumn{3}{|c|}{$\mathrm{O}_{2}^{-}(\mathrm{nmol} / \mathrm{mL})$} \\
\hline STEMI & $8.90 \pm 6.91(7.25)$ & \multirow{4}{*}{ Kruskal-Wallis test: $P=0.284$} \\
\hline NSTEMI & $9.68 \pm 9.45(7.58)$ & \\
\hline UA & $10.38 \pm 0.57(10.54)$ & \\
\hline Control & $10.63 \pm 22.90(5.27)$ & \\
\hline \multicolumn{3}{|c|}{$\mathrm{H}_{2} \mathrm{O}_{2}(\mathrm{nmol} / \mathrm{mL})$} \\
\hline STEMI & $2.70 \pm 1.66(2.14)$ & $\begin{array}{l}\text { Kruskal-Wallis test: } P=\mathbf{0 . 0 0 0}^{* *} \\
\text { Mann-Whitney U test: }\end{array}$ \\
\hline NSTEMI & $2.41 \pm 2.04(1.98)$ & $\begin{array}{l}\text { STEMI versus NSTEMI } P=0.181 \\
\text { STEMI versus UA } P=0.235\end{array}$ \\
\hline UA & $5.06 \pm 7.37(1.66)$ & $\begin{aligned} \text { STEMI versus Control } P & =\mathbf{0 . 0 0 0} \\
\text { NSTEMI versus UA } P & =0.872\end{aligned}$ \\
\hline Control & $8.11 \pm 7.52(5.21)$ & $\begin{array}{c}\text { NSTEMI versus Control } P=\mathbf{0 . 0 0 0}^{* *} \\
\text { UA versus Control } P=\mathbf{0 . 0 0 0}^{* *}\end{array}$ \\
\hline \multicolumn{3}{|c|}{$\mathrm{NO}_{2}^{-}(\mathrm{nmol} / \mathrm{mL})$} \\
\hline STEMI & $13.16 \pm 7.57(12.65)$ & \multirow{4}{*}{ ONE way ANOVA: $P=0.081$} \\
\hline NSTEMI & $13.12 \pm 9.62(9.69)$ & \\
\hline UA & $9.54 \pm 6.95(7.22)$ & \\
\hline Control & $15.98 \pm 6.05(17.20)$ & \\
\hline \multicolumn{3}{|c|}{ TBARS $(\mu \mathrm{mol} / \mathrm{mL})$} \\
\hline STEMI & $3.42 \pm 2.61(2.69)$ & $\begin{array}{l}\text { Kruskal-Wallis test: } P=\mathbf{0 . 0 0 0}{ }^{* *} \\
\text { Mann-Whitney } U \text { test: }\end{array}$ \\
\hline NSTEMI & $2.96 \pm 2.47(2.21)$ & $\begin{array}{l}\text { STEMI versus NSTEMI } P=0.999 \\
\text { STEMI versus UA } P=0.999\end{array}$ \\
\hline UA & $2.10 \pm 0.56(2.30)$ & $\begin{aligned} \text { STEMI versus Control } P & =\mathbf{0 . 0 0 0 * *} \\
\text { NSTEMI versus UA } P & =0.999\end{aligned}$ \\
\hline Control & $1.34 \pm 0.47(1.19)$ & $\begin{array}{l}\text { NSTEMI versus Control } P=\mathbf{0 . 0 0 0}^{* *} \\
\text { UA versus Control } P=\mathbf{0 . 0 0 0}^{* *}\end{array}$ \\
\hline \multicolumn{3}{|c|}{$\mathrm{SOD}\left(\mathrm{U} / \mathrm{g} \mathrm{Hb} \times 10^{3}\right)$} \\
\hline STEMI & $185.04 \pm 154.82(124.54)$ & $\begin{array}{l}\text { Kruskal-Wallis test: } P=\mathbf{0 . 0 0 0}^{* *} \\
\text { Mann-Whitney } U \text { test: }\end{array}$ \\
\hline
\end{tabular}


Table 4: Continued.

\begin{tabular}{|c|c|c|}
\hline & $X \pm \mathrm{SD}$ (median) & Sig. \\
\hline NSTEMI & $140.03 \pm 129.84(87.91)$ & $\begin{array}{l}\text { STEMI versus NSTEMI } P=0.069 \\
\text { STEMI versus UA } P=\mathbf{0 . 0 3 2}\end{array}$ \\
\hline UA & $67.20 \pm 20.95(66.34)$ & $\begin{aligned} \text { STEMI versus Control } P & =\mathbf{0 . 0 0 0} \\
\text { NSTEMI versus UA } P & =0.615\end{aligned}$ \\
\hline Control & $3078.21 \pm 2664.35(2433.71)$ & $\begin{array}{l}\text { NSTEMI versus Control } P=\mathbf{0 . 0 0 0}^{* *} \\
\text { UA versus Control } P=\mathbf{0 . 0 0 0}^{* *}\end{array}$ \\
\hline \multicolumn{3}{|c|}{ CAT $\left(\mathrm{U} / \mathrm{g} \mathrm{Hb} \times 10^{3}\right)$} \\
\hline STEMI & $5.94 \pm 5.94(3.25)$ & \multirow{4}{*}{ Kruskal-Wallis test: $P=0.159$} \\
\hline NSTEMI & $5.30 \pm 4.14(4.37)$ & \\
\hline UA & $4.38 \pm 2.65(4.12)$ & \\
\hline Control & $7.80 \pm 5.10(6.87)$ & \\
\hline
\end{tabular}

TABLE 5: Results of uni- and multivariant logistic regression related to the effects of different type ACSs to changes in examined biochemical parameters (B-unstandardized regression coefficient; $\mathrm{CI}$ - confidence interval; ${ }^{*} P<0.005 ; * * P<0.001$ ).

\begin{tabular}{|c|c|c|c|c|}
\hline \multirow{2}{*}{ Parameter } & \multicolumn{2}{|c|}{ Univariate logistic regression } & \multicolumn{2}{|c|}{ Multivariate logistic regression } \\
\hline & $B(95 \% \mathrm{CI})$ & Sig. & $B(95 \% \mathrm{CI})$ & Sig. \\
\hline vWfAct & $-0.006(-0.008-(-0.003))$ & $P=0.000^{* *}$ & $0.000(-0.004-0.003)$ & $P=0.948$ \\
\hline vWfAg & $-0.006(-0.007-(-0.005))$ & $P=0.000^{* *}$ & $-0.004(-0.006-(-0.001))$ & $P=0.007^{* *}$ \\
\hline NO & $0.027(0.001-0.053)$ & $P=\mathbf{0 . 0 3 8}^{*}$ & $-0.002(-0.026-0.023)$ & $P=0.897$ \\
\hline $\mathrm{O}_{2}$ & $0.003(-0.010-0.016)$ & $P=0.648$ & - & - \\
\hline $\mathrm{H}_{2} \mathrm{O}_{2}$ & $0.099(0.064-0.133)$ & $P=\mathbf{0 . 0 0 0}^{* *}$ & $0.072(0.013-0.131)$ & $P=0.018$ \\
\hline TBARS & $-0.161(-0.220-(-0.102))$ & $P=0.000^{* *}$ & $-0.100(-0.183-(-0.017))$ & $P=0.019^{*}$ \\
\hline SOD & $0.000(0.000-0.000)$ & $P=0.000^{* *}$ & $0.001(0.000-0.001)$ & $P=0.262$ \\
\hline CAT & $0.015(-0.024-0.053)$ & $P=0.450$ & - & - \\
\hline
\end{tabular}

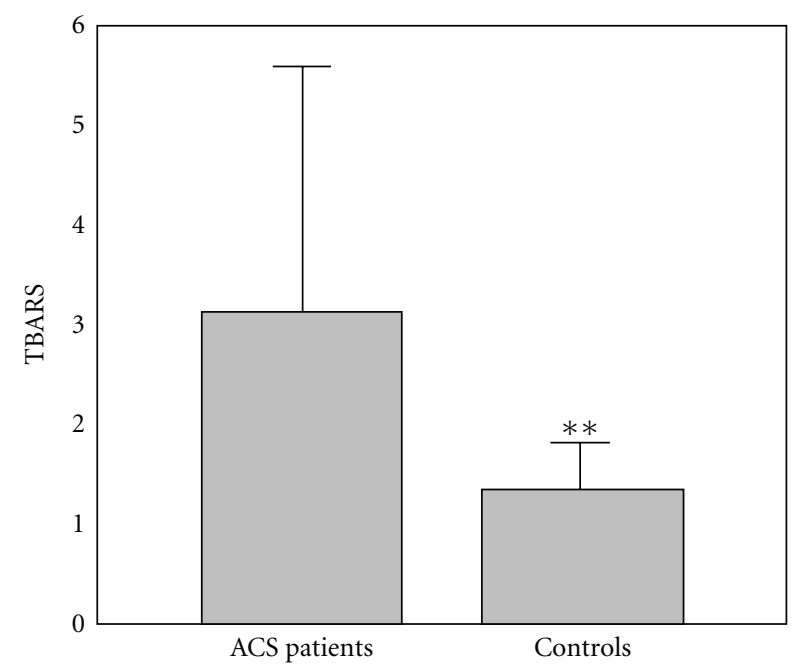

FIgURE 6: Values of index of lipid peroxidation (TBARS) levels $(\mu \mathrm{mol} / \mathrm{mL})$ in group of ACSs patient and in group of control sub-jects (mean $+\mathrm{SD})$. Compared with control subjects, ACSs patients had statistically higher TBARS compared with control subjects $\left(3.12 \pm 2.45(2.48) \mathrm{U} / \mathrm{g} \mathrm{Hb} \times 10^{3}\right.$ compared with $1.34 \pm 0.47$ (1.19) $\mathrm{U} / \mathrm{g} \mathrm{Hb} \times 10^{3} ;$-test; $\left.{ }^{* *} P<0.01\right)$.

test's ability to revel healthy subjects, was $97.5 \%$ for vWfAct and $100.00 \%$ for vWfAg. Receiver operating characteristic (ROC) curve (Figure 9) shows discriminative ability of the test.
Table 4 shows levels of investigated parameters in groups of patients with different type of ACSs. Results of uniand multivariant logistic regression related to the effects of diff-erent type of ACSs existence to changes in examined biochemical parameters are shown in Table 5. Univariant logistic regression marked vWfAg, vWfAct, $\mathrm{NO}_{2}{ }^{-}, \mathrm{H}_{2} \mathrm{O}_{2}$, TBARS, and SOD as significant, while multivariant analysis showed that only vWfAg and TBARS were under independent effect of ACSs type.

Table 6 shows data about investigated biochemical parameters in ACSs patients who survived and who deceased. There was no significant difference in any investigated biochemical parameter between these groups.

Results of univariant logistic regression regarding effects of levels of biochemical parameters on outcome (survival or lethal event) of ACSs patients showed that no biochemical parameter was revealed as significant, so multivariant logistic regression was not performed (Table 7).

\section{Discussion}

Biomarkers play a pivotal role in the diagnosis and treatment of patients with cardiovascular disease [24]. Advances in our understanding of the pathophysiology of ACSs have led to the marked increase in development of biomarkers for diagnosis, risk stratification, therapeutic decision making, and assessment of clinical outcomes [25-27]. A lot of new markers measuring various components of the acute 
TABLE 6: Levels of investigated biochemical parameters in ACSs patients who survived and who deceased.

\begin{tabular}{|c|c|c|}
\hline Subjects & $X \pm \mathrm{SD}($ median$)$ & Sig. \\
\hline \multicolumn{3}{|c|}{ vWfAct (\%) } \\
\hline Survivors $(n=111)$ & $172.00 \pm 83.94(168.00)$ & \multirow{2}{*}{ Mann-Whitney $U$ test, $P=0.708$} \\
\hline Deceased $(n=4)$ & $189.80 \pm 105.94(175.00)$ & \\
\hline \multicolumn{3}{|c|}{ vWfAg $(\%)$} \\
\hline Survivors & $274.86 \pm 120.70(241.00)$ & \multirow{2}{*}{ Mann-Whitney $U$ test, $P=0.119$} \\
\hline Deceased & $395.30 \pm 182.16(416.00)$ & \\
\hline \multicolumn{3}{|c|}{$\mathrm{NO}_{2}^{-}(\mathrm{nmol} / \mathrm{mL})$} \\
\hline Survivors & $12.68 \pm 7.86(12.32)$ & \multirow{2}{*}{$t$-test, $P=0.998$} \\
\hline Deceased & $12.67 \pm 10.28(8.18)$ & \\
\hline \multicolumn{3}{|c|}{$\mathrm{O}_{2}^{-}(\mathrm{nmol} / \mathrm{mL})$} \\
\hline Survivors & $9.15 \pm 10.68(6.59)$ & \multirow{2}{*}{ Mann-Whitney $U$ test, $P=0.150$} \\
\hline Deceased & $15.42 \pm 28.24(3.62)$ & \\
\hline \multicolumn{3}{|c|}{$\mathrm{H}_{2} \mathrm{O}_{2}(\mathrm{nmol} / \mathrm{mL})$} \\
\hline Survivors & $2.99 \pm 3.53(2.20)$ & \multirow{2}{*}{ Mann-Whitney $U$ test, $P=0.918$} \\
\hline Deceased & $2.16 \pm 0.56(2.05)$ & \\
\hline \multicolumn{3}{|c|}{ TBARS $(\mu \mathrm{mol} / \mathrm{mL})$} \\
\hline Survivors & $4.26 \pm 3.39(2.95)$ & \multirow{2}{*}{ Mann-Whitney $U$ test, $P=0.394$} \\
\hline Deceased & $5.24 \pm 3.24(5.06)$ & \\
\hline \multicolumn{3}{|c|}{$\mathrm{SOD}\left(\mathrm{U} / \mathrm{g} \mathrm{Hb} \times 10^{3}\right)$} \\
\hline Survivors & $157.55 \pm 125.22(107.45)$ & \multirow{2}{*}{ Mann-Whitney $U$ test, $P=0.836$} \\
\hline Deceased & $175.82 \pm 198,86(118.03)$ & \\
\hline \multicolumn{3}{|c|}{$\mathrm{CAT}\left(\mathrm{U} / \mathrm{g} \mathrm{Hb} \times 10^{3}\right)$} \\
\hline Survivors & $6.16 \pm 5.22(4.00)$ & \multirow{2}{*}{ Mann-Whitney $U$ test, $P=0.073$} \\
\hline Deceased & $11.30 \pm 7.36(10.00)$ & \\
\hline
\end{tabular}

TABLE 7: Univariant logistic regression regarding effects of biochemical parameters on outcome of ACSs patients $(\exp B$-relative risk; CI-confidence interval).

\begin{tabular}{lcc}
\hline \multirow{2}{*}{ Parameter } & \multicolumn{2}{c}{ Univariant logistic regression } \\
& $\exp B(95 \% \mathrm{CI})$ & Sig. \\
\hline vWfAct & $1.002(0.992-1.013)$ & $P=0.647$ \\
vWfAg & $1.006(1.000-1.013)$ & $P=0.052$ \\
$\mathrm{NO}_{2}^{-}$ & $1.000(0.892-1.121)$ & $P=0.998$ \\
$\mathrm{O}_{2}$ & $1.026(0.979-1.075)$ & $P=0.291$ \\
$\mathrm{H}_{2} \mathrm{O}_{2}$ & $0.846(0.447-1.599)$ & $P=0.606$ \\
$\mathrm{TBARS}_{\text {SOD }}$ & $1.083(0.843-1.391)$ & $P=0.531$ \\
CAT & $1.001(1.995-1.008)$ & $P=0.757$ \\
\hline
\end{tabular}

atherothrombotic event have been described, and novel biomarkers of endothelial activation, inflammation, coagulation, and platelet activation are intensively investigated [2831]. Among other perspective prognostic biomarkers that have not been incorporated into routine clinical use yet, von Willebrand factor rises considerable attention.

Many different vWf-dependent laboratory assays have been developed to correctly diagnose and classify von Willebrand disease [32]. However, when investigating vWf as a risk factor for cardiovascular disease, assays for plasma vWf antigen and plasma vWf activity are used in most cases [1]. ACSs patients in our study had significantly elevated levels of both vWfAct and vWfAg compared with healthy control subjects. Levels of vWfAct did not differ significantly among patients with different type of ACSs; vWfAct was elevated only in STEMI (ST elevation MI) and NSTEMI (non-ST elevation MI) ACSs patients, while patients with unstable angina had vWfAct levels similar to control subjects. Regarding vWfAg, there were significant differences in its level among patients with different types of ACSs as well as between controls and STEMI and NSTEMI patients. Only vWfAg levels of patients with UA did not differ from controls. The results of our study are in consent with previously reported data. Spiel et al. [1] and Paulinska et al. [16] reported that the published vWf data $[10,11,33-37]$ shows that patients with acute myocardial infarction (AMI) have markedly increased vWf values compared with unstable angina (UA) and coronary artery disease (CAD) patients as well as compared with healthy control subjects. That vWf is biochemical parameter that distinguishes well between the healthy and people with ACSs our study proved not only by assessing differences in its levels between ACSs patients and controls, but also by com-paring the frequency of the existance of elevated vWf levels in these two groups as well as by counting its specificity and sensitivity. Sensitivity of vWfAg, as an indicator of its ability to reveal patients with disease, was $86 \%$, while its specificity, as an indicator of its ability to reveal healthy subjects, was $100 \%$. Sensitivity of vWfAct was significantly 


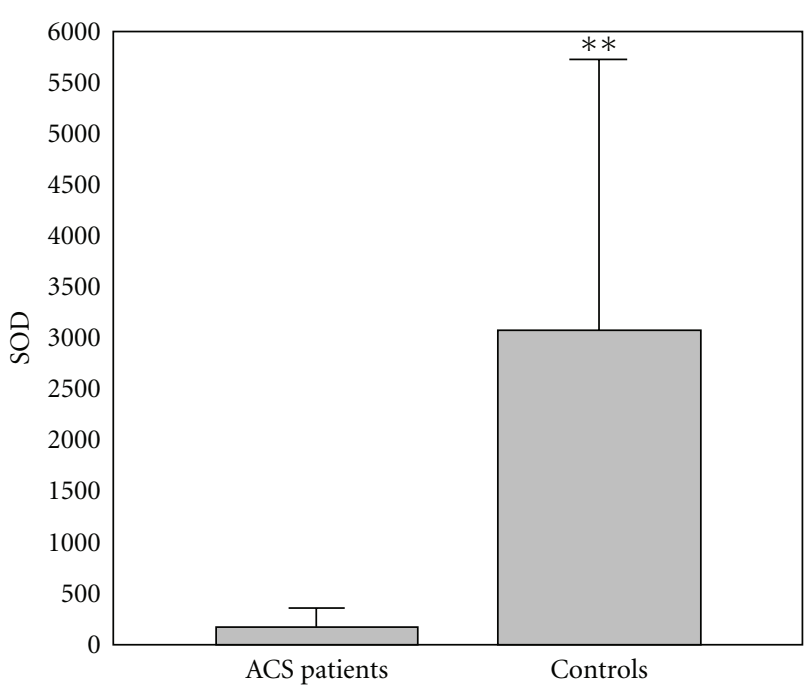

Figure 7: Values of superoxide dismutase activity $\left(\mathrm{U} / \mathrm{g} \mathrm{Hb} \times 10^{3}\right)$ in group of ACSs patient and in group of control subjects (mean + SD). Compared with control subjects, ACSs patients had statistically lower SOD activity $\left(156.83 \pm 140.94\right.$ (89.54) $\mathrm{U} / \mathrm{g} \mathrm{Hb} \times 10^{3}$ compared with $3078.21 \pm 2664.35$ (2433.71) U/g Hb $\times 10^{3}$; Mann-Whitney $U$ test; $\left.{ }^{* *} P<0.01\right)$.

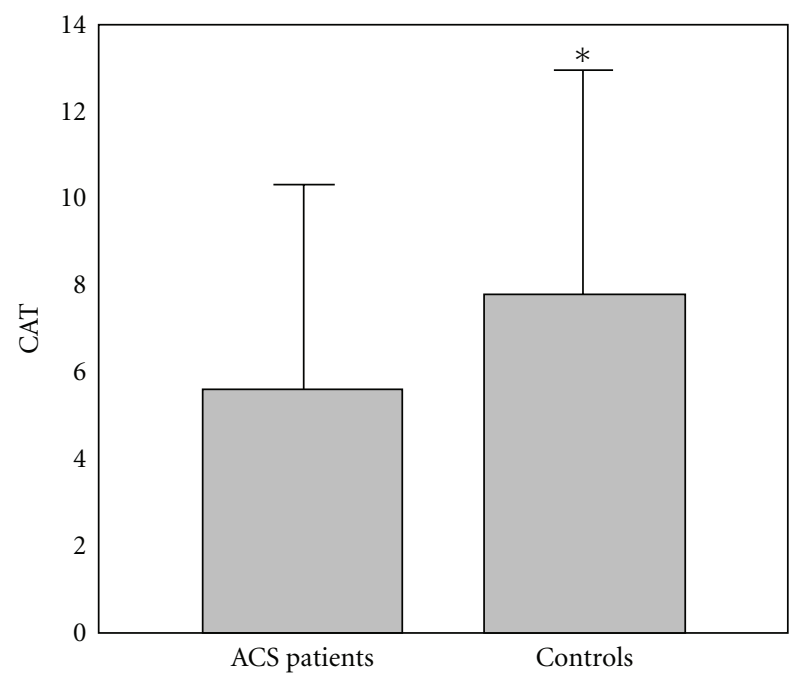

Figure 8: Values of catalase activity $\left(\mathrm{U} / \mathrm{g} \mathrm{Hb} \times 10^{3}\right)$ in group of ACSs patient and in group of control subjects (mean + SD). Compared with control subjects, ACSs patients had statistically lower CAT activity $\left(5.55 \pm 4.99(4.00) \mathrm{U} / \mathrm{g} \mathrm{Hb} \times 10^{3}\right.$ compared with $7.80 \pm 5.10(6.87) \mathrm{U} / \mathrm{g} \mathrm{Hb} \times 10^{3}$; Mann-Whitney $U$ test; $\left.{ }^{*} P<0.05\right)$.

lower, but its specificity was also very high (97.5\%). As it can also be seen from Figure 9 that shows ROC curves for vWfAct and vWfAg, the strength of vWfAg as an indicator of ACSs existance is very high. Results of logistic regression also highlighted this parameter as significant—univariant logistic regression showed that type of ACSs affects both vWfAct and vWfAg levels, but multivariant regression marked only vWfAg as the one whose change is under independent effect of ACSs type not due to existance of other cofactors.

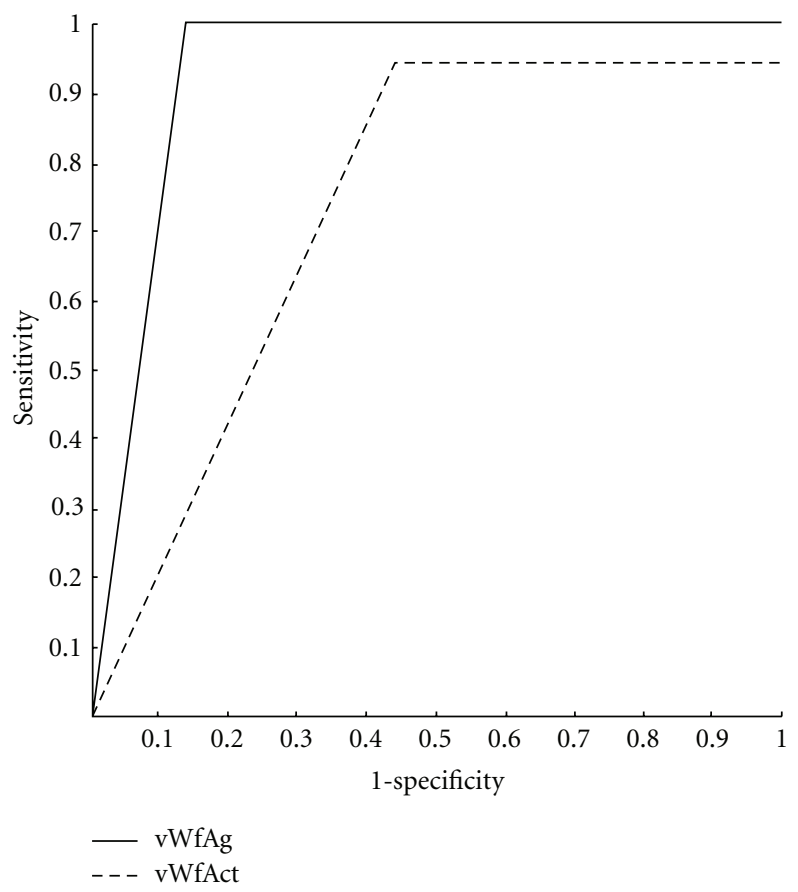

Figure 9: Based on the data about sensitivity and specificity of the test (measuring vWfAct and vWfAg levels), receiver operating characteristic (ROC) curve as an indicator of the discriminating ability of the vWfAct and vWfAct test was obtained. ROC curve shows that the strength of vWfAg as an indicator of ACSs existence is very high.

The results of previous studies regarding prognostic value of vWf for cardiovascular events are equivocal. Many studies found increased relative risk in subjects with the highest levels of vWf $[6,38,39]$, but in the majority of studies, the association between vWf and CHD risk disappeared after adjustment for conventional risk factors $[8,9]$. However, in contrast to results of studies performed in the general population, in patients with preexisting vascular disease, vWf revealed as significantly predictive parameter for adverse cardiac events, including death [13, 14, 40-42]. Our study was not prospective, but since 4 patients died few days after admission, we compared their admission levels of investigated biochemical parameters with levels of patients that survived. No statistical difference was found, neither in vWfAct and vWfAg levels, nor in levels of redox parameters.

The second part of our investigation related to the assessment of subjects' redox state. Oxidative stress has been suggested to play an important role in the development of more than two hundred acute and chronic human diseases as well as in aging [21-23,43-46]. The results of our study showed that ACSs patients had significantly less efficient antioxidative defence system compared with controls (significantly lower levels of SOD and CAT activity) which resulted in significantly increased levels of lipid peroxidation. Furthermore, ACSs patients had significantly lower levels of nitric oxide (nitrites), which is an indicator of endothelial dysfunction. Suprisingly, $\mathrm{H}_{2} \mathrm{O}_{2}$ levels of ACSs patients were significantly lower than controls' The fact that 
ACSs patients had lower $\mathrm{NO}$ and $\mathrm{H}_{2} \mathrm{O}_{2}$ levels may be brought into connection with vWf levels, since reactive oxygen species and NO are involved in the regulation of vWf release. It was previously suggested that the blockade of nitric oxide enhances the stimulated release of vWf in humans $[47,48]$, that is, $\mathrm{NO}$ exerts inhibitory effects on vWf release [5]. So, is thought for $\mathrm{H}_{2} \mathrm{O}_{2}$ [5]. ACSs patients were deficient in $\mathrm{NO}$ and $\mathrm{H}_{2} \mathrm{O}_{2}$ compared with controls, so $\mathrm{NO}$ and $\mathrm{H}_{2} \mathrm{O}_{2}$ inhibition of vWf release was probably lower. When comparing oxidative status of patients with different ACSs types, only SOD differed between STEMI and UA patients (UA patients had lower SOD activity). On the other hand, whenever the difference among 4 groups (3 ACSs groups and control group; Table 4) was found, it related to differences between every group of ACSs patients and controls. These results suggest that ACSs patients are under higher oxidative stress compared with control subjects, no matter which type of ACSs they have. However, although ACSs patients differed from controls in a few oxidative stress parameters, only TBARS was found to be under the independent effect of ACSs type.

The results of our study point out to von Willebrand factor antigen as strong indicator of existance of any kind of ACSs. This supports the implementation of vWf in clinical routine and into therapeutic targets. Results related to the investigation of oxidative stress in ACSs patients suggest that antioxidant supplementation is needed to improve the antioxidant defence, since enzymatic antioxidant defense is compromised and lipid peroxidation consequently increased in those patients.

\section{Patients and Methods}

4.1. Subjects. The research was carried out within a group of 115 patients who were consecutively admitted to the Intensive Care Unit of University Hospital Center "Kragujevac", Serbia. All patients met the criteria for ACSs diagnosis (the presence of two out of these three criteria is enough to diagnose ACSs): (1) chest pain, (2) electrocardiographic changes (ST elevation or depression $\geq 1 \mathrm{~mm}$, or $\mathrm{T}$ wave inversion), and (3) serum cardiac markers changes (creatine kinase $(\mathrm{CK})$, creatine kinase $\mathrm{MB}(\mathrm{CK}-\mathrm{MB})$, and troponin $\mathrm{T}(\mathrm{TnT})$ ) [49]. The diagnosis of STEMI was defined as the concurrence of prolonged chest pain or discomfort with persistent ST-segment elevation of greater than $1 \mathrm{~mm}$ in 2 or more contiguous leads or with presumed new left bundle-branch block with cardiac enzymes (total creatine kinase and creatine kinase $\mathrm{MB}$ fraction) above twice the upper normal limit [50]. The diagnosis of NSTEMI included the presence of typical angina at rest associated with acute and transient ST-segment or T-wave changes with cardiac enzymes above twice the upper normal limit, raised troponin I levels to at least "high risk" values $(>0.6 \mathrm{ng} / \mathrm{mL})$, or both [50]. Patients with clinical or electrocardiographic (ECG) features of non-STEMI but with normal cardiac enzymes plus normal troponin levels were classified as UA [50].

The study was approved by Ethical committee of University Hospital Center "Kragujevac", Serbia.
4.2. Protocol. After admission to hospital patients were taken a blood sample from which von Willebrand factor activity (vWfAct), von Willebrand antigen (vWfAg), levels of nitric oxide (NO), superoxide anion radical $\left(\mathrm{O}_{2}{ }^{-}\right)$, hydrogen peroxide $\left(\mathrm{H}_{2} \mathrm{O}_{2}\right)$, index of lipid peroxidation (TBARS), superoxide dismutase activity (SOD), and catalase activity (CAT) were determined.

4.3. Biochemical Assays. Blood samples were taken from the antecubital veins into Vacutainer test tube containing sodium citrate anticoagulant. Blood was centrifuged to separate plasma and red blood cells (RBCs).

4.4. von Willebrand Factor Activity and von Willebrand Factor Antigen Determination. Determination of vWfAct and vWfAg was performed using commercial assay kit (HemosIL 0020004700 and 0020002300) on ACL Elite Pro apparatus manufactured by Instrumentation Laboratory, Bedford, Mass, USA. vWfAct and vWfAg results are reported in \% of normality.

4.5. Nitric Oxide Determination. Nitric oxide (NO) decomposes rapidly to form stable metabolite nitrite/nitrate products. Nitrite $\left(\mathrm{NO}_{2}{ }^{-}\right)$was determined as an index of nitric oxide production with Griess reagent [51]. $0.1 \mathrm{~mL} 3 \mathrm{~N}$ PCA (Perchloride acid), $0.4 \mathrm{~mL} 20 \mathrm{mM}$ EDTA (ethylenediaminetetraacetic acid), and $0.2 \mathrm{~mL}$ plasma were put on ice for $15 \mathrm{~min}$ then centrifuged $15 \mathrm{~min}$ at $6000 \mathrm{rpm}$. After pouring off the supernatant, $220 \mu \mathrm{L} \mathrm{K}_{2} \mathrm{CO}_{3}$ was added. Nitrites were measured at $550 \mathrm{~nm}$. Distilled water was used as a blank probe.

4.6. Superoxide Anion Radical Determination. The level of superoxide anion radical $\left(\mathrm{O}_{2}{ }^{-}\right)$was measured using NBT (nitro blue tetrazolium) reaction in TRIS-buffer combined with plasma samples and read at $530 \mathrm{~nm}$ [52].

4.7. Hydrogen Peroxide Determination. The protocol for measurement of hydrogen peroxide $\left(\mathrm{H}_{2} \mathrm{O}_{2}\right)$ is based on oxidation of phenol red in the presence of horseradish peroxidase [53]. Two hundred $\mu \mathrm{L}$ sample with $800 \mu \mathrm{L}$ PRS (phenol red solution) and $10 \mu \mathrm{L}$ POD (horse radish peroxidase) were combined $(1: 20)$. The level of $\mathrm{H}_{2} \mathrm{O}_{2}$ was measured at $610 \mathrm{~nm}$.

4.8. Index of Lipid Peroxidation (Thiobarbituric Acid Reactive Substances, TBARS). The degree of lipid peroxidation in plasma was estimated by measuring of thiobarbituric acid reactive substances (TBARS) using 1\% TBA (Thiobarbituric Acid) in $0.05 \mathrm{NaOH}$, incubated with plasma at $100^{\circ} \mathrm{C}$ for $15 \mathrm{~min}$ and read at $530 \mathrm{~nm}$. Distilled water was used as a blank probe. TBA extract was obtained by combining $0.8 \mathrm{~mL}$ plasma and $0.4 \mathrm{~mL}$ TCA (trichloro acetic acid), then samples were put on ice for 10 minutes and centrifuged for $15 \mathrm{~min}$ at $6000 \mathrm{rpm}$. This method was described previously [54].

4.9. Determination of Antioxidant Enzymes. Isolated RBCs were washed three times with 3 volumes of ice-cold 
$0.9 \mathrm{mmol} / \mathrm{L} \mathrm{NaCl}$, and hemolysates containing about $50 \mathrm{~g} \mathrm{Hb} / \mathrm{L}$ (prepared according to McCord and Fridovich [55]) were used for the determination of catalase (CAT) activity. CAT activity was determined according to Beutler [56]. Lysates were diluted with distilled water $(1: 7 \mathrm{v} / \mathrm{v})$ and treated with chloroform-ethanol $(0.6: 1 \mathrm{v} / \mathrm{v})$ to remove haemoglobin [57]. Then, $50 \mu \mathrm{L}$ catalase buffer, $100 \mu \mathrm{L}$ sample, and $1 \mathrm{~mL} 10 \mathrm{mM} \mathrm{H}_{2} \mathrm{O}_{2}$ were added to the samples. Detection was performed at $360 \mathrm{~nm}$. Distilled water was used as a blank probe. Superoxide dismutase (SOD) activity was determined by the epinephrine method of Misra and Fridovich [58]. A hundred $\mu \mathrm{L}$ lysate and $1 \mathrm{~mL}$ carbonate buffer were mixed, and then, $100 \mu \mathrm{L}$ of epinephrine was added. Detection was performed at $470 \mathrm{~nm}$.

4.10. Statistics. The statistical analysis was performed with SPSS 10.0 for Windows. Results are expressed as the means \pm standard deviation (median). Data on figures is presented as mean + standard deviation. After checking data distribution, the appropriate parametric or nonparametric test was used. The differences between two groups were assessed using $t$ test or Mann-Whitney test, while the differences between more than three groups were assessed using one-way ANOVA or Kruskal-Wallis test. For ANOVA posthoc analysis, Bonferroni test was used. To define the parameters that mostly change in ACSs, univariant logistic regression was used. Parameters that were marked as significant in univariant logistic regression entered multivariant logistic regression. Multivariant logistic regression marked parameters that were under independent effect of ACSs. $\chi^{2}$ test was used to assess the difference in frequency of elevated levels of vWfAct and vWfAg. Based on the data about this frequency, sensitivity and specificity of the test (vWfAct and vWfAg test) were calculated. Based on the data about sensitivity and specificity of the test, the receiver operating characteristics (ROC) curve was determined.

\section{Abbreviations}

ACSs: Acute coronary syndromes

STEMI: ST-segment elevation myocardial infarction

NSTEMI: Non-ST-segment elevation myocardial infarction

UA: Unstable angina

vWfAct: von Willebrand factor activity

vWfAg: von Willebrand factor antigen

SOD: $\quad$ Superoxide dismutase

CAT: $\quad$ Catalase

ROS: $\quad$ Reactive oxygen species

CVD: Cardiovascular disease

CHD: Coronary heart disease

ROC: Receiver operating characteristics.

\section{Acknowledgment}

This work was supported by Grant no. 175043 from the Ministry of Science and Technical Development of the Republic of Serbia.

\section{References}

[1] A. O. Spiel, J. C. Gilbert, and B. Jilma, "von Willebrand factor in cardiovascular disease: focus on acute coronary syndromes," Circulation, vol. 117, no. 11, pp. 1449-1459, 2008.

[2] U. Derhaschnig and B. Jilma, "Assessment of platelets and the endothelium in patients presenting with acute coronary syndromes-is there a future?" Thrombosis and Haemostasis, vol. 102, no. 6, pp. 1144-1148, 2009.

[3] A. Blann, "von Willebrand factor and the endothelium in vascular disease," British Journal of Biomedical Science, vol. 50, no. 2, pp. 125-134, 1993.

[4] G. Y. Lip and A. Blann, "von Willebrand factor: a marker of endothelial dysfunction in vascular disorders?" Cardiovascular Research, vol. 34, no. 2, pp. 255-265, 1997.

[5] U. M. Vischer, "von Willebrand factor, endothelial dysfunction, and cardiovascular disease," Journal of Thrombosis and Haemostasis, vol. 4, no. 6, pp. 1186-1193, 2006.

[6] A. R. Folsom, K. K. Wu, W. D. Rosamond, A. R. Sharrett, and L. E. Chambless, "Prospective study of hemostatic factors and incidence of coronary heart disease: the atherosclerosis risk in communities (ARIC) study," Circulation, vol. 96, no. 4, pp. 1102-1108, 1997.

[7] A. Rumley, G. D. Lowe, P. M. Sweetnam, J. W. Yarnell, and R. P. Ford, "Factor VIII, von Willebrand factor and the risk of major ischaemic heart disease in the caerphilly heart study," British Journal of Haematology, vol. 105, no. 1, pp. 110-116, 1999.

[8] P. E. Morange, C. Simon, M. C. Alessi et al., "Endothelial cell markers and the risk of coronary heart disease: the prospective epidemiological study of myocardial infarction (PRIME) study," Circulation, vol. 109, no. 11, pp. 1343-1348, 2004.

[9] P. H. Whincup, J. Danesh, M. Walker et al., "von Willebrand factor and coronary heart disease: prospective study and metaanalysis," European Heart Journal, vol. 23, no. 22, pp. 17641770, 2002.

[10] K. W. Lee, G. Y. Lip, M. Tayebjee, W. Foster, and A. D. Blann, "Circulating endothelial cells, von Willebrand factor, interleukin-6, and prognosis in patients with acute coronary syndromes," Blood, vol. 105, no. 2, pp. 526-532, 2005.

[11] H. Sakai, S. Goto, J. Y. Kim et al., "Plasma concentration of von Willebrand factor in acute myocardial infarction," Thrombosis and Haemostasis, vol. 84, no. 2, pp. 204-209, 2000.

[12] J. H. Jansson, T. K. Nilsson, and O. Johnson, "von Willebrand factor in plasma: a novel risk factor for recurrent myocardial infarction and death," British Heart Journal, vol. 66, no. 5, pp. 351-355, 1991.

[13] B. Wiman, T. Andersson, J. Hallqvist, C. Reuterwall, A. Ahlbom, and U. de Faire, "Plasma levels of tissue plasminogen activator/plasminogen activator inhibitor-1 complex and von Willebrand factor are significant risk markers for recurrent myocardial infarction in the stockholm heart epidemiology program (SHEEP) study," Arteriosclerosis, Thrombosis, and Vascular Biology, vol. 20, no. 8, pp. 2019-2023, 2000.

[14] I. Fuchs, M. Frossard, A. Spiel, E. Riedmuller, A. N. Laggner, and B. Jilma, "Platelet function in patients with acute coronary syndrome (ACS) predicts recurrent ACS," Journal of Thrombosis and Haemostasis, vol. 4, pp. 2547-2552, 2006.

[15] U. M. Vischer and P. de Moerloose, "von Willebrand factor: from cell biology to the clinical management of von Willebrand's disease," Critical Reviews in Oncology/Hematology, vol. 30, no. 2, pp. 93-109, 1999. 
[16] P. Paulinska, A. Spiel, and B. Jilma, "Role of von Willebrand factor in vascular disease," Hamostaseologie, vol. 29, no. 1, pp. 32-38, 2009.

[17] U. M. Vischer, L. Jornot, C. B. Wollheim, and J. M. Theler, "Reactive oxygen intermediates induce regulated secretion of von Willebrand factor from cultured human vascular endothelial cells," Blood, vol. 85, no. 11, pp. 3164-3172, 1995.

[18] K. Matsushita, C. N. Morrell, R. J. A. Mason et al., "Hydrogen peroxide regulation of endothelial exocytosis by inhibition of N-ethylmaleimide sensitive factor," Journal of Cell Biology, vol. 170, no. 1, pp. 73-79, 2005.

[19] S. X. Yang, J. Yan, S. S. Deshpande, K. Irani, and C. J. Lowenstein, "Racl regulates the release of Weibel-Palade bodies in human aortic endothelial cells," Chinese Medical Journal, vol. 117, no. 8, pp. 1143-1150, 2004.

[20] M. Valgimigli, E. Merli, P. Malagutti et al., "Endothelial dysfunction in acute and chronic coronary syndromes: evidence for a pathogenetic role of oxidative stress," Archives of Biochemistry and Biophysics, vol. 420, no. 2, pp. 255-261, 2003.

[21] N. S. Dhalla, R. M. Temsah, and T. Netticadan, "Role of oxidative stress in cardiovascular diseases," Journal of Hypertension, vol. 18, no. 6, pp. 655-673, 2000.

[22] G. Kojda and D. Harrison, "Interactions between NO and reactive oxygen species: pathophysiological importance in atherosclerosis, hypertension, diabetes and heart failure," Cardiovascular Research, vol. 43, no. 3, pp. 562-571, 1999.

[23] M. M. Elahi, Y. X. Kong, and B. M. Matata, "Oxidative stress as a mediator of cardiovascular disease," Oxidative Medicine and Cellular Longevity, vol. 2, no. 5, pp. 259-269, 2009.

[24] K. Maiese, "Marking the onset of oxidative stress: biomarkers and novel strategies," Oxidative Medicine and Cellular Longevity, vol. 2, no. 1, p. 1, 2009.

[25] K. T. Moe and P. Wong, "Current trends in diagnostic biomarkers of acute coronary syndrome," Annals of the Acade-my of Medicine Singapore, vol. 39, no. 3, pp. 210-215, 2010.

[26] M. P. Bonaca and D. A. Morrow, "Defining a role for novel biomarkers in acute coronary syndromes," Clinical Chemistry, vol. 54, no. 9, pp. 1424-1431, 2008.

[27] J. L. Anderson, C. D. Adams, E. M. Antman et al., "ACC/AHA 2007 guidelines for the management of patients with unstable angina/non-ST-elevation myocardial infarction. A report of the American College of Cardiology/American Heart Association Task Force on Practice," Journal of the American College of Cardiology, vol. 50, no. 7, pp. e1-e157, 2007.

[28] E. J. Armstrong, D. A. Morrow, and M. S. Sabatine, "Inflammatory biomarkers in acute coronary syndromes-part II. Acute-phase reactants and biomarkers of endothelial cell activation," Circulation, vol. 113, no. 7, pp. e152-e155, 2006.

[29] E. J. Armstrong, D. A. Morrow, and M. S. Sabatine, "Inflammatory biomarkers in acute coronary syndromespart IV. Matrix metalloproteinases and biomarkers of platelet activation," Circulation, vol. 113, no. 9, pp. e382-e385, 2006.

[30] L. M. Biasucci, "CDC/AHA workshop on markers of inflammation and cardiovascular disease: application to clinical and public health practice: clinical use of inflammatory markers in patients with cardiovascular diseases: a background paper," Circulation, vol. 110, no. 25, pp. e560-e567, 2004.

[31] R. Hurks, W. Peeters, W. J. Derksen et al., "Biobanks and the search for predictive biomarkers of local and systemic outcome in atherosclerotic disease," Thrombosis and Haemostasis, vol. 101, no. 1, pp. 48-54, 2009.
[32] E. J. Favaloro, "Laboratory identification of von Willebrand disease: technical and scientific perspectives," Seminars in Thrombosis and Hemostasis, vol. 32, no. 5, pp. 456-471, 2006.

[33] K. W. Lee, A. D. Blann, and G. Y. Lip, "Inter-relationships of indices of endothelial damage/dysfunction [circulating endothelial cells, von Willebrand factor and flow-mediated dilatation] to tissue factor and interleukin- 6 in acute coronary syndromes," International Journal of Cardiology, vol. 111, no. 2, pp. 302-308, 2006.

[34] S. Yazdani, A. D. Simon, L. Kovar, W. Wang, A. Schwartz, and L. E. Rabbani, "Percutaneous interventions alter the hemostatic profile of patients with unstable versus stable angina," Journal of the American College of Cardiology, vol. 30, no. 5, pp. 1284-1287, 1997.

[35] K. Eto, T. Isshiki, H. Yamamoto et al., "AJvW-2, an anti-vWF monoclonal antibody, inhibits enhanced platelet aggregation induced by high shear stress in platelet-rich plasma from patients with acute coronary syndromes," Arteriosclerosis, Thrombosis, and Vascular Biology, vol. 19, no. 4, pp. 877-882, 1999.

[36] N. D. Vaziri, S. C. Kennedy, D. Kennedy, and E. Gonzales, "Coagulation, fibrinolytic, and inhibitory proteins in acute myocardial infarction and angina pectoris," American Journal of Medicine, vol. 93, no. 6, pp. 651-657, 1992.

[37] M. Frossard, I. Fuchs, J. M. Leitner et al., "Platelet function predicts myocardial damage in patients with acute myocardial infarction," Circulation, vol. 110, no. 11, pp. 1392-1397, 2004.

[38] A. M. Thogersen, J. H. Jansson, K. Boman et al., "High plasminogen activator inhibitor and tissue plasminogen activator levels in plasma precede a first acute myocardial infarction in both men and women: evidence for the fibrinolytic system as an independent primary risk factor," Circulation, vol. 98, no. 21, pp. 2241-2247, 1998.

[39] J. Danesh, J. G. Wheeler, G. M. Hirschfield et al., "C-reactive protein and other circulating markers of inflammation in the prediction of coronary heart disease," New England Journal of Medicine, vol. 350, no. 14, pp. 1387-1397, 2004.

[40] S. G. Thompson, J. Kienast, S. D. Pyke, F. Haverkate, and J. C. van de Loo, "Hemostatic factors and the risk of myocardial infarction or sudden death in patients with angina pectoris: european concerted action on thrombosis and disabilities angina pectoris study group," The New England Journal of Medicine, vol. 332, pp. 635-641, 1995.

[41] J. H. Jansson, T. K. Nilsson, and O. Johnson, "von Willebrand factor in plasma: a novel risk factor for recurrent myocardial infarction and death," British Heart Journal, vol. 66, no. 5, pp. 351-355, 1991.

[42] M. Cortellaro, C. Boschetti, E. Cofrancesco, C. Zanussi, M. Catalano, and G. de Gaetano, "The PLAT study: hemostatic function in relation to atherothrombotic ischemic events in vascular disease patients: principal results: PLAT study group: Progetto Lombardo Atero-Trombosi (PLAT) study group," Arteriosclerosis, Thrombosis, and Vascular Biology, vol. 12, pp. 1063-1070, 1992.

[43] I. Dalle-Donne, R. Rossi, R. Colombo, D. Giustarini, and A. Milzani, "Biomarkers of oxidative damage in human disease," Clinical Chemistry, vol. 52, no. 4, pp. 601-623, 2006.

[44] K. B. Pandey and S. I. Rizvi, "Markers of oxidative stress in erythrocytes and plasma during aging in humans," Oxidative Medicine and Cellular Longevity, vol. 3, no. 1, pp. 2-12, 2010. 
[45] V. P. Reddy, A. Beyaz, G. Perry, M. S. Cooke, L. M. Sayre, and M. A. Smith, "The role of oxidative damage to nucleic acids in the pathogenesis of neurological disease," Oxidative Medicine and Cellular Longevity, vol. 1, no. 6, pp. 535-544, 2005.

[46] P. Gomes, S. Simão, E. Silva et al., "Aging increases oxidative stress and renal expression of oxidant and antioxidant enzymes that are associated with an increased trend in systolic blood pressure," Oxidative Medicine and Cellular Longevity, vol. 2, no. 3, pp. 138-145, 2009.

[47] B. Jilma, T. Pernerstorfer, E. Dirnberger et al., "Effects of histamine and nitric oxide synthase inhibition on plasma levels of von Willebrand factor antigen," Journal of Laboratory and Clinical Medicine, vol. 131, no. 2, pp. 151-156, 1998.

[48] T. Pernerstorfer, P. Stohlawetz, S. Kapiotis, H. G. Eichler, and B. Jilma, "Partial inhibition of nitric oxide synthase primes the stimulated pathway of VWF-secretion in man," Atherosclerosis, vol. 148, no. 1, pp. 43-47, 2000.

[49] A. Kumar and C. P. Cannon, "Acute coronary syndromes: diagnosis and management_-part I," Mayo Clinic Proceedings, vol. 84, no. 10, pp. 917-938, 2009.

[50] J. S. Alpert, K. Thygesen, E. Antman, and J. P. Bassand, "Myocardial infarction redefined-a consensus document of the Joint European Society of Cardiology/American College of Cardiology committee for the redefinition of myocardial infarction," Journal of the American College of Cardiology, vol. 36, pp. 959-969, 2000.

[51] L. C. Green, D. A. Wagner, J. Glogowski, P. L. Skipper, J. S. Wishnok, and S. R. Tannenbaum, "Analysis of nitrate, nitrite, and $[15 \mathrm{~N}]$ nitrate in biological fluids," Analytical Biochemistry, vol. 126, no. 1, pp. 131-138, 1982.

[52] C. Auclair and E. Voisin, "Nitroblue tetrazolium reduction," in Handbook of Methods for Oxygen Radical Research, R. A. Greenvvald, Ed., pp. 123-132, CRC Press, Boka Raton, Fla, USA, 1985.

[53] E. Pick and Y. A. Keisari, "A simple colorimetric method for the measurement of hydrogen peroxide produced by cells in culture," Journal of Immunological Methods, vol. 38, no. 1-2, pp. 161-170, 1980.

[54] H. Ohkawa, N. Ohishi, and K. Yagi, "Assay for lipid peroxides in animal tissues by thiobarbituric acid reaction," Analytical Biochemistry, vol. 95, no. 2, pp. 351-358, 1979.

[55] J. M. McCord and I. Fridovich, "The utility of superoxide dismutase in studying free radical reactions. I. Radicals generated by the interaction of sulfite, dimethyl sulfoxide, and oxygen," Journal of Biological Chemistry, vol. 244, no. 22, pp. 6056-6063, 1969.

[56] E. Beutler, "Catalase," in Red Cell Metabolism, A Manual of Biochemical Methods, E. Beutler, Ed., pp. 105-106, Grune and Stratton, New York, NY, USA, 1982.

[57] M. Tsuchihashi, “Zur Kernntnis der blutkatalase," Biochemische Zeitschrift, vol. 140, pp. 65-72, 1923.

[58] H. P. Misra and I. Fridovich, "The role of superoxide anion in the autoxidation of epinephrine and a simple assay for superoxide dismutase," Journal of Biological Chemistry, vol. 247, no. 10, pp. 3170-3175, 1972. 


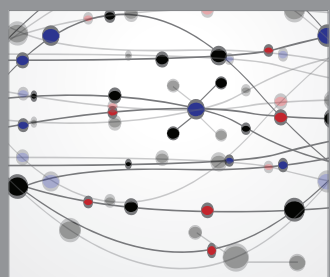

The Scientific World Journal
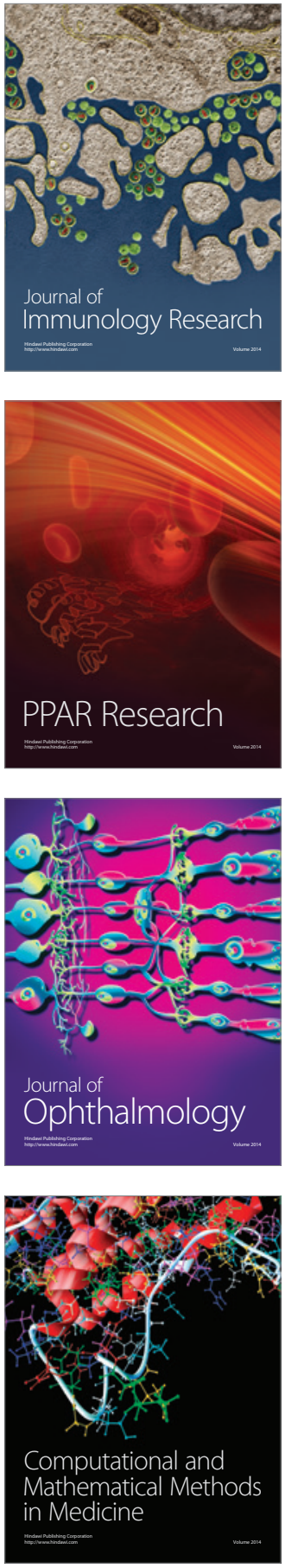

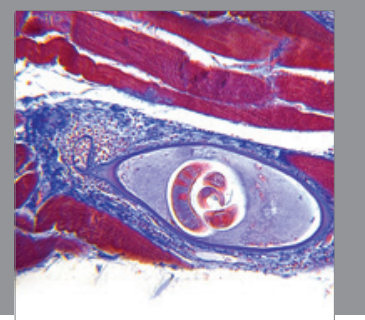

Gastroenterology

Research and Practice
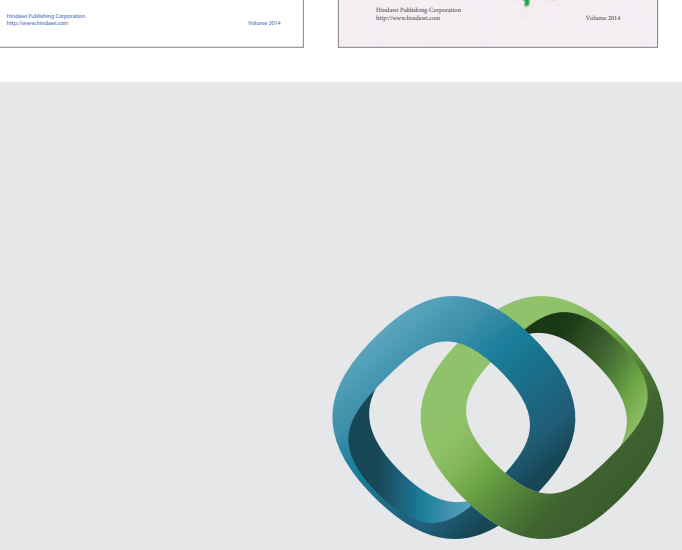

\section{Hindawi}

Submit your manuscripts at

http://www.hindawi.com
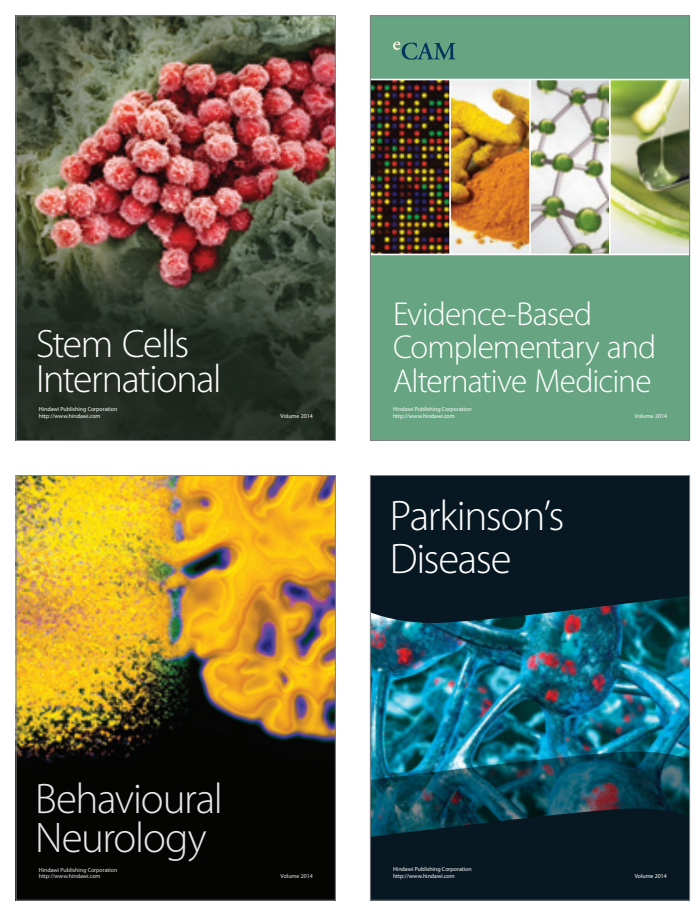

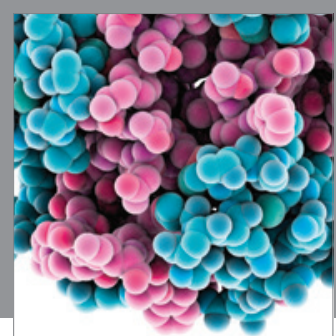

Journal of
Diabetes Research

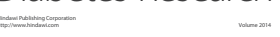

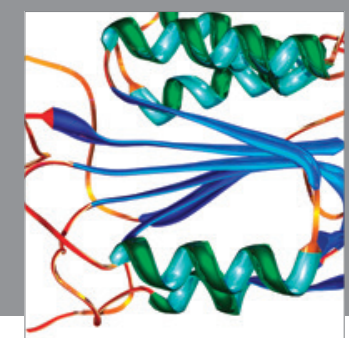

Disease Markers
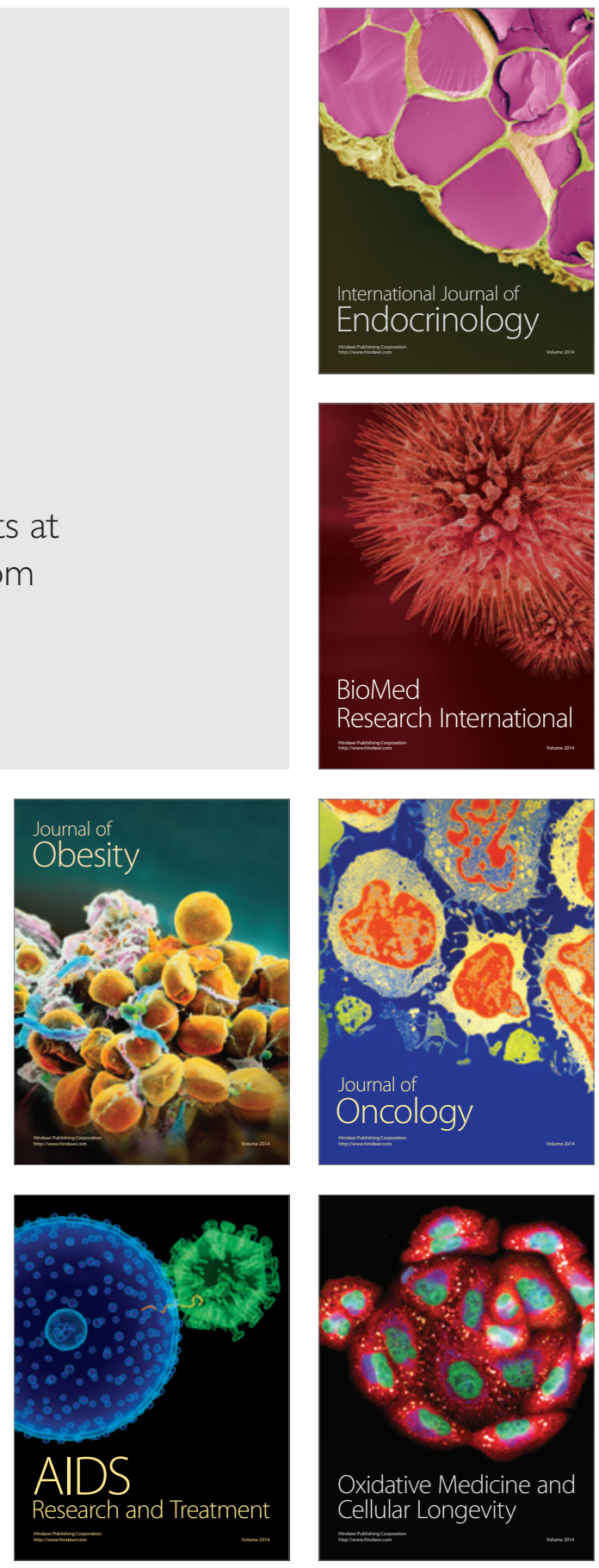